OPEN ACCESS

Edited by: Detlev Boison Legacy Health, United States

Reviewed by: Iris Müller,

Purdue University, United States Deniz Yilmazer-Hanke, Universität UIm, Germany

*Correspondence: Aizhong Liu lazroy@live.cn

Received: 17 July 2018 Accepted: 21 November 2018 Published: 04 December 2018

Citation:

Pan X, Kaminga AC, Wen SW and Liu A (2018) Catecholamines in Post-traumatic Stress Disorder: A Systematic Review and Meta-Analysis.

Front. Mol. Neurosci. 11:450. doi: 10.3389/fnmol.2018.00450

\section{Catecholamines in Post-traumatic Stress Disorder: A Systematic Review and Meta-Analysis}

\author{
Xiongfeng Pan ${ }^{1}$, Atipatsa C. Kaminga ${ }^{1,2}$, Shi Wu Wen ${ }^{1,3}$ and Aizhong Liu ${ }^{1 *}$ \\ ${ }^{1}$ Department of Epidemiology and Health Statistics, Xiangya School of Public Health, Central South University, Changsha, \\ China, ${ }^{2}$ Department of Mathematics and Statistics, Mzuzu University, Mzuzu, Malawi, ${ }^{3}$ Department of Obstetrics and \\ Gynaecology and Ottawa Hospital Research Institute, University of Ottawa, Ottawa, ON, Canada
}

Studies on the association between post-traumatic stress disorder (PTSD) and levels of catecholamines have yielded inconsistent results. The aim of this study was to conduct a systematic review and meta-analysis to assess whether concentrations of the catecholamines dopamine, norepinephrine, and epinephrine are associated with PTSD. This study searched relevant articles in the following databases: PubMed, Embase, Web of Science, and Psyc-ARTICLES. Each database was searched from its inception to September, 2018. Data related to catecholamine concentrations were extracted for patients with PTSD and the controls to calculate standardized mean differences and to evaluate effect sizes. A meta-analysis was then performed to compare the concentration of each catecholamine between the two groups in blood and/or urine samples. Heterogeneity was quantified using $l^{2}$ and its significance was tested using the Q statistics. Subgroup analyses of the types of controls, PTSD assessment tools, and assayed methods used in the studies were performed to explore sources of heterogeneity among studies. Random-effects models were used to combine results from selected studies. A total of 1,388 articles were identified, of which 27 were included in the final analysis. Heterogeneity was high; hence random-effects models were used to combine results of selected studies. Results revealed significantly higher norepinephrine levels in people with PTSD than in the controls [standardized mean difference (SMD) $=0.35,95 \%$ confidence interval $(\mathrm{Cl})$ : 0.13 to $0.57, p=0.002$ ]. No difference was found in dopamine and epinephrine concentrations between the two groups. Elevated norepinephrine levels may be an important indicator for PTSD.

Keywords: post-traumatic stress disorder, catecholamines, dopamine, epinephrine, norepinephrine, systematic review, meta-analysis

\section{INTRODUCTION}

Post-traumatic stress disorder (PTSD) is a bio-psychosocial dysfunction that can develop in people after they have been exposed to traumatic events, including natural disasters, warfare, traffic accidents, sexual assault, and other threats (McFarlane, 2014; Pollard et al., 2016; Hardy and Mueser, 2017). PTSD includes four symptom clusters: re-experiencing, avoidance, negative alterations in cognition/mood, and alterations in arousal and reactivity (Cordova et al., 2017; Onton et al., 2018). Even worse, PTSD creates more problems than fear memory, and may threaten 
or damage the quality of life (Burstajn and First, 2014). For instance, patients with PTSD are commonly at a higher risk for intentional self-harm, and suicide (Butterfield et al., 2005). Therefore, PTSD is a major public health problem worldwide, and diagnosing it timely may help to treat or prevent the disease as soon as possible to reduce the burden of the disease.

Several instruments have been used to diagnose PTSD including the diagnostic criteria published in the fifth edition of the Diagnostic, and Statistical Manual of Mental Disorders (DSM-5) and the 11th revision of the International Classification of Diseases (ICD-11) (Hyland et al., 2018). Currently, DSM5 is the most recommended diagnostic tool to clinicians for diagnosing PTSD. Nonetheless, based on recent advances made in cognitive neuroscience, biomarkers such as catecholamines, cortisol, interleukin 6, and interferon- $\gamma$ measured in the saliva, serum, urinary, plasma, and cerebrospinal fluid have become new promising options for the screening, treatment, and prevention of PTSD (Kao et al., 2015; Olff and van Zuiden, 2017; Pan et al., 2018). Catecholamines have been identified as a group of monoaminergic neurotransmitters, which include dopamine, noradrenaline, and adrenaline (Highland et al., 2015). The sympathetic nervous system stimulates the release of the catecholamines epinephrine, norepinephrine, and dopamine to mediate adaptive responses to acute stressors. They are also linked with long-term memory of events that induce strong emotions such as fear (Ouyang et al., 2012). They are known to be important in the modulation of the mechanisms underlying different states of PTSD. In addition, stress-responsive neurotransmitters released during emotional arousal are thought to enhance the consolidation of fear memory (Matthews et al., 2012; McLaughlin et al., 2015). Likewise, preclinical evidence has shown that the consolidation and retrieval of traumatic memories are regulated by an interaction between the noradrenergic, glucocorticoid and dopaminergic systems (Eiden, 2013; Hauer et al., 2014).

The tendency of catecholamines to associate with PTSD brought many hypotheses (Norrholm et al., 2013; Bandelow et al., 2017). Among them, dysfunction of the dopaminergic system is one of the most important hypotheses. Dopamine is involved in the regulation of fear-conditioning in a number of brain areas including the amygdala, nucleus accumbens (NAC), ventral tegmental area (VTA), and medial prefrontal cortex (mPFC) (Johnson et al., 2011; Eiden, 2013; Aubry et al., 2016). Furthermore, hyperresponsiveness in the dopaminergic system is common in individuals who have been exposed to stress, which was associated with PTSD symptoms such as restlessness, nightmares, fear memory, and impulsivity (Pezze and Feldon, 2004). Higher dopaminergic activity may contribute to alterations in memory and other cognitive functions, anhedonia, and hypervigilance, all of which are symptoms observed in PTSD patients (Spivak et al., 1999; Sher et al., 2005).

Moreover, existing data suggest that not only was dopamine found to be associated with PTSD, but also higher levels of norepinephrine and epinephrine were observed in PTSD patients (Lee et al., 2016; Gold et al., 2018).

In general, epinephrine from adrenal medulla is identified as the hallmark of acute stress, which is accompanied by noradrenaline release from the locus coeruleus and allows responses to acute stressors to be translated into long-term PTSD symptoms, via increased localized activation, and regulation of circuits in the central nervous system (CNS) (Geracioti et al., 2008).

A possible explanation for this is the over activation of noradrenaline receptors in the amygdala, hippocampus, hypothalamus, striatum, and prefrontal cortex, which could be associated with the flashbacks, and nightmares frequently experienced by those with persistence of PTSD symptoms (O’Donnell et al., 2004; Lee et al., 2017). Previous studies indicated a higher incidence of PTSD among women than among their male counterparts (Mendoza et al., 2016). However, in biological models of PTSD, it is unclear whether sex-mediated output of catecholamines is affected in PTSD (Murphy et al., 2018). To date the biological mechanisms underlying these differential risk factors remain poorly understood.

Taken together, several recent studies investigating the association between catecholamine levels and PTSD found inconsistent results (Glover et al., 2003; Osuch et al., 2009). In some of those studies, individuals with PTSD had higher levels of catecholamines than individuals without trauma exposure or those exposed to trauma but did not develop PTSD (Lemieux and Coe, 1995; De Bellis et al., 1999; Glover et al., 2003; Young and Breslau, 2004). In fact, those with trauma exposure who did not develop PTSD had lower catecholamine levels than those without trauma exposure, indicating a potential mechanism for resilience (Young and Breslau, 2004). However, other studies found that individuals with PTSD had lower levels of catecholamines than the controls (Murburg et al., 1995; Videlock et al., 2008; Osuch et al., 2009).

To date, there is no meta-analysis which investigated the role of catecholamine levels in PTSD (Eiden, 2013). Therefore, there was need to address these inconsistencies using the method of meta-analysis, which is the gold-standard for data aggregation.

The objective of this study is, therefore, to conduct a comprehensive meta-analysis for the first time on the literature related to the relationship between catecholamine concentrations and PTSD, and to quantify the strength of this relationship.

\section{MATERIALS AND METHODS}

\section{Search Strategy and Selection Criteria}

This systematic review and meta-analysis followed the Preferred Reporting Items for Systematic Reviews, and Meta-Analyses (PRISMA) guidelines (Moher et al., 2010). We searched four electronic databases: PubMed, Embase, Web of Science, and Psyc-ARTICLES. Online electronic databases were searched until September 2018 for articles published in English. Experienced librarians designed these searches, which used the following keywords: (Catecholamine[Title/Abstract] OR Catecholamines[Title/Abstract] OR Dopamine[Title/Abstract] OR Dopamin[Title/Abstract] OR Epinephrine[Title/Abstract] OR Norepinephrine[Title/Abstract] OR Noradrenaline [Title/Abstract] OR Noradrenalin[Title/Abstract] OR Adrenaline[Title/Abstract] OR Adrenalin[Title/Abstract]) AND (PTSD[Title] OR post-traumatic stress disorder[Title] OR 
posttraumatic stress disorder[Title]). These search terms were adapted for the other databases, for which the detailed search strategies are shown in the Supplemental Material.

\section{Eligibility Criteria}

Studies were eligible for this systematic review, and metaanalysis if they reported (1) PTSD cases and controls, (2) PTSD diagnostic criteria, and (3) the mean and standard deviation (SD) of catecholamine concentrations or if these were provided by the authors upon request. Studies were excluded if (1) they were review articles, and case reports, (2) they studied PTSD in combination with other mental illnesses, (3) the hypothalamicpituitary-adrenal (HPA) axis was pharmacologically challenged (e.g., by dexamethasone) before catecholamines measurement, (4) they did not study humans, and (5) they were gray literatures (non-published literatures).

Two reviewers [XP and AC] independently screened articles, and selected eligible studies. In case of disagreement the final decision was made by consultation with a third party [AL].

\section{Data Abstraction}

For the purpose of this meta analysis, two independent investigators [XP and $\mathrm{AC}]$ extracted the following information according to the inclusion criteria specified above: (1) name of the first author and publication year; (2) country of the study; (3) sample characteristics: sample size, type of catecholamine studied, mean catecholamine concentration and corresponding standard deviation (mean, SD); (4) PTSD participants: trauma type, mean age and corresponding standard deviation (mean, SD), and gender; (5) PTSD assessment method; (6) catecholamine sample collection and assay methods: interassay variation, intra-assay variation, sensitivity, and storage temperatures. All the information was organized using EpiData 3.0, and then recorded into Excel spreadsheets.

\section{Quality Evaluation}

Each eligible study was evaluated based on the three broad perspectives: (1) Selection: representativeness of the sample, adequacy of the case definition, and appropriateness of the selection of the controls, and the definition of the controls; (2) Comparability: whether the subjects in different outcome groups are comparable based on the study design or analysis, and whether confounding factors are controlled; (3) Outcome: appropriateness of the method of ascertainment for outcomes of cases and controls, and appropriateness of ascertainment of outcomes of variables and non-response rate. According to the pre-specified criteria, studies were graded as high, moderate, and low quality based on the scores 7-9, 36 , and $0-3$, respectively. Two investigators [XP and $\mathrm{AC}$ ] independently assessed and graded the eligible studies. Any inconsistencies between them were resolved by group discussion with a third party. Seven studies were judged to be of high-quality, and three of them received a total score of 8 . Furthermore, 19 were of moderate quality, and 1 was of low quality.

\section{Statistical Analysis}

All analyses were carried out in R software (version R i386 3.4.2). First, overall meta-analyses comparing catecholamines concentrations between people with PTSD and the controls were performed. Studies used different methods for measuring catecholamines concentration. Therefore, the standardized mean difference (SMD) was used to assess their effect size, which was calculated as Cohen's d (Higgins et al., 2003). The effect size was considered large when it was $>0.8$, moderate when it was between 0.5 and 0.8 , and low when it was lower than 0.5. Heterogeneity across studies was assessed using Q statistics and quantified by calculating $I^{2}$. The $I^{2}$ is presented in percentages with a zero percent $(0 \%)$ value indicating no observed heterogeneity, and higher values indicating increasing heterogeneity. Generally, heterogeneity is categorized as $<25 \%$ (low), 25\% 75\% (moderate) and $>75 \%$ (high) (Higgins et al., 2003). Also, $\tau^{2}$ statistic was used to assess the total amount of heterogeneity. In the case of significant high heterogeneity $\left(I^{2}>50 \%\right)$, the random-effects model was used with a restricted maximum-likelihood estimator to obtain a pooled estimate of the effect sizes in the eligible studies, when $I^{2}>50 \%$. Otherwise, the randomfixed-effects model was used. The pooled estimated effect size was reported with the corresponding $95 \%$ confidence interval (Higgins et al., 2003).

In addition, sources of heterogeneity related to some characteristics reported in the eligible studies were explored by means of subgroup analyses. Thus, the following subgroups were defined according to the availability of data from the eligible studies: trauma type, control type, sample type, assay method, and storage temperature, etc. However, when the number of included studies in a subgroup analysis was $<2$, the statistical efficiency was very low (Higgins et al., 2009). Thus, some studies failed to fulfill the criteria for inclusion in subgroup analyses. Additionally, sensitivity analysis was performed to examine whether the stability of the results was influenced by any single study or a cluster of studies sharing some characteristics. The sensitivity analysis involved repeating the meta-analysis by omitting each study in turn.

Finally, potential publication bias was assessed by examining the symmetry of funnel plots when the number of trials reporting the primary outcomes was 10 or more. This was then verified with the Egger's linear regression test (Egger et al., 1997). In all analyses, the level of significance for the effect size estimation was set at the $5 \%$, and all tests were two-sided.

\section{RESULTS}

\section{Literature Search}

Our search identified a total of 1,388 relevant articles. Of these, 220 were from PubMed, 635 from Embase, 490 from Web of Science, and 43 from PsycARTICLES. The 163 duplicated reports were deleted. Further assessment of the 1,225 abstracts resulted in the exclusion of 938 studies that failed to meet the inclusion criteria. The remaining 287 full text articles were then reviewed independently by two authors [XP and $\mathrm{AC}$ ], which has resulted in the exclusion of further articles. Altogether 59 articles were excluded for not reporting means (SDs), which included studies, 
whose authors have not replied to the e-mail request before this submission. Another 119 articles were excluded for having unrelated topics, 39 articles for not assessing catecholamines, 11 articles because they were review articles, 19 articles for not comparing patients and controls, and 13 articles for not reporting results for controls. A total of 27 articles that met the inclusion criteria were included in the final analyses (Figure 1).

\section{Characteristics of Eligible Studies}

Most articles reported the following characteristics: trauma type, control type, PTSD participants: trauma type, mean, and SD (mean, SD) of age of participants, sex distribution of participants, time of catecholamine collection, catecholamine collection and assay methods, inter-assay variation, intra-assay variation, sensitivity, and storage temperature. Table $\mathbf{1}$ gives an overview of the parameters reported in the 27 eligible studies.

\section{Overall Comparison}

Dopamine levels were reported in seven studies (Figure 2A), for which this study found a non-significant difference in dopamine concentrations between PTSD participants and controls. The seven studies accounted for a total of 656 participants $(275$ PTSD patients and 381 controls), in which dopamine was measured. Epinephrine levels between the two groups were measured in 17 studies (Figure 2B), which corresponded to a total of 1,031 participants (451 PTSD patients, and 562 controls) for epinephrine. Although in these studies higher epinephrine concentrations were observed in PTSD individuals as compared to controls, this result was not significant. The overall analysis comparing concentrations of dopamine $(\mathrm{SMD}=0.14 ; 95 \% \mathrm{CI}$ $[-0.02,0.30], P=0.088)$ and epinephrine (SMD $=0.19$; 95\%CI $[-0.11,0.49], P=0.207)$ between patients with PTSD and the controls did not indicate any significant differences, but revealed considerable heterogeneity $\left(I^{2}=45.50 \%\right.$ and $I^{2}=$ $69.70 \%$, respectively).

Furthermore, norepinephrine concentrations were compared in 23 studies between the two groups (Figure 2C). Altogether 592 PTSD patients and 802 controls were included in the studies on norepinephrine levels. Results revealed significantly higher norepinephrine concentrations in people with PTSD than in controls (SMD $=0.35,95 \% \mathrm{CI}: 0.130 .57, p=0.002$ ), but with high heterogeneity $\left(I^{2}=62.8 \%\right)$.
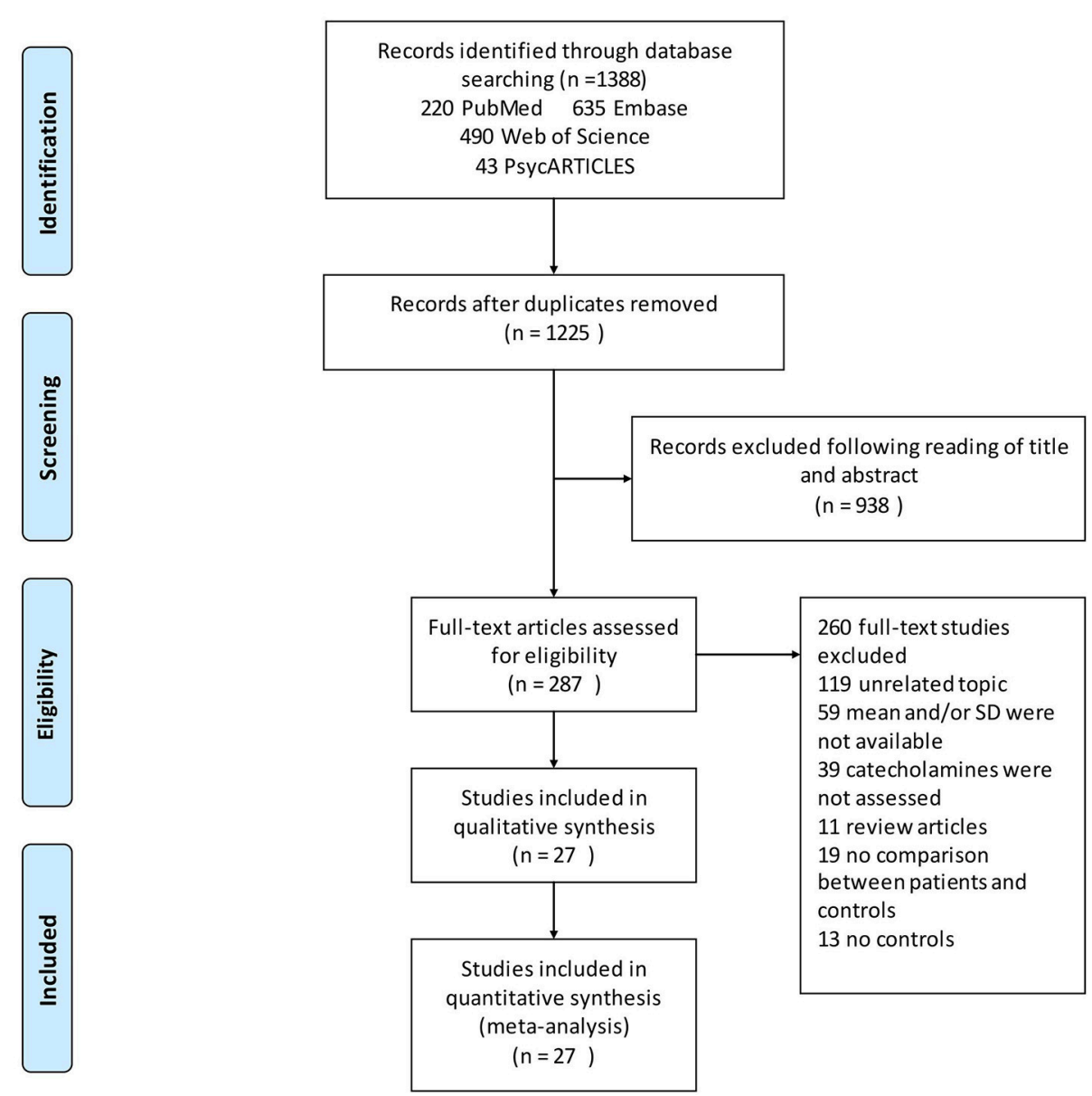

FIGURE 1 | Flowchart of study selection. Showing the process by which relevant studies retrieved from the databases were assessed and selected, or excluded. Preferred reporting items for systematic reviews and meta-analyses (PRISMA) diagram for study search. 


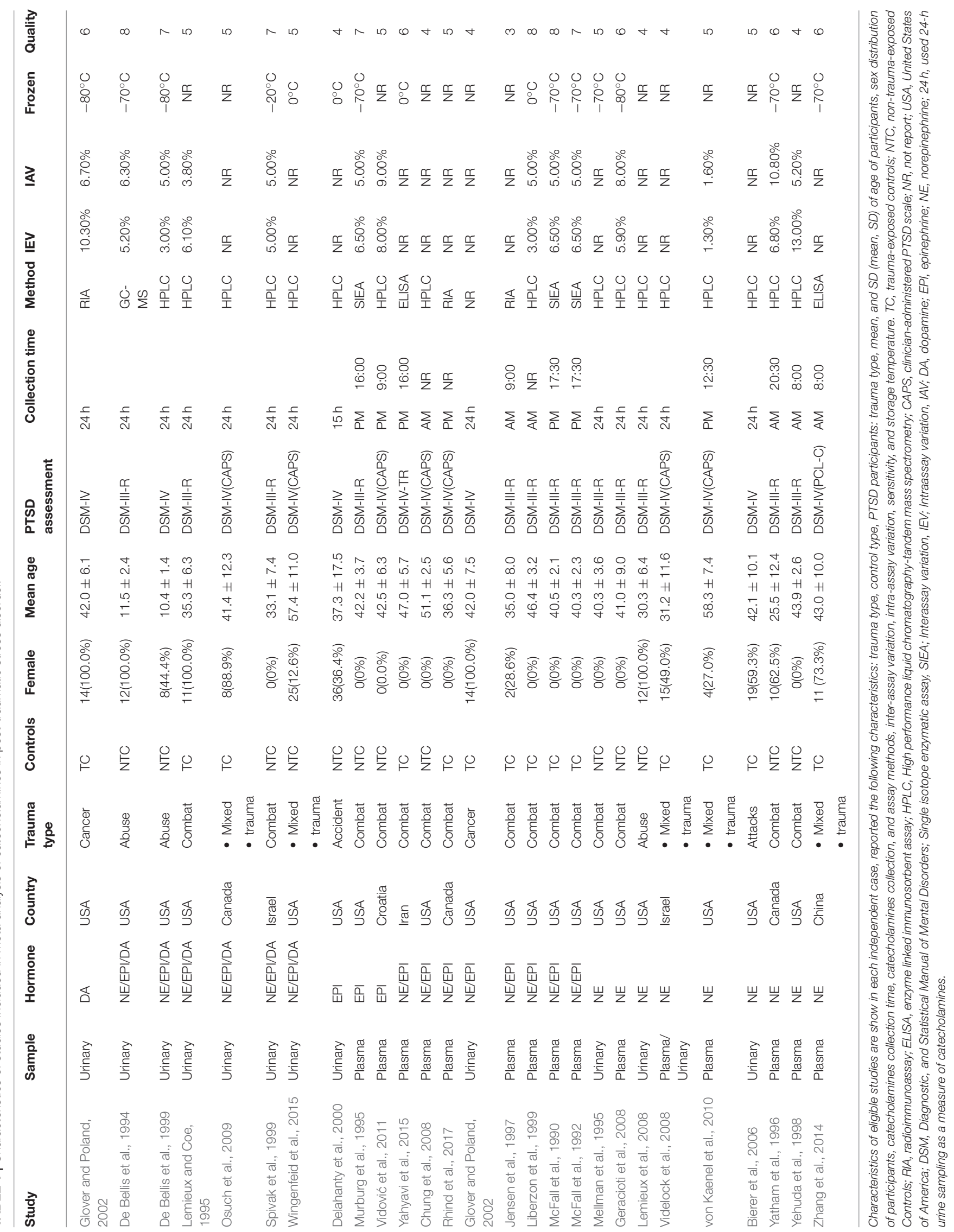




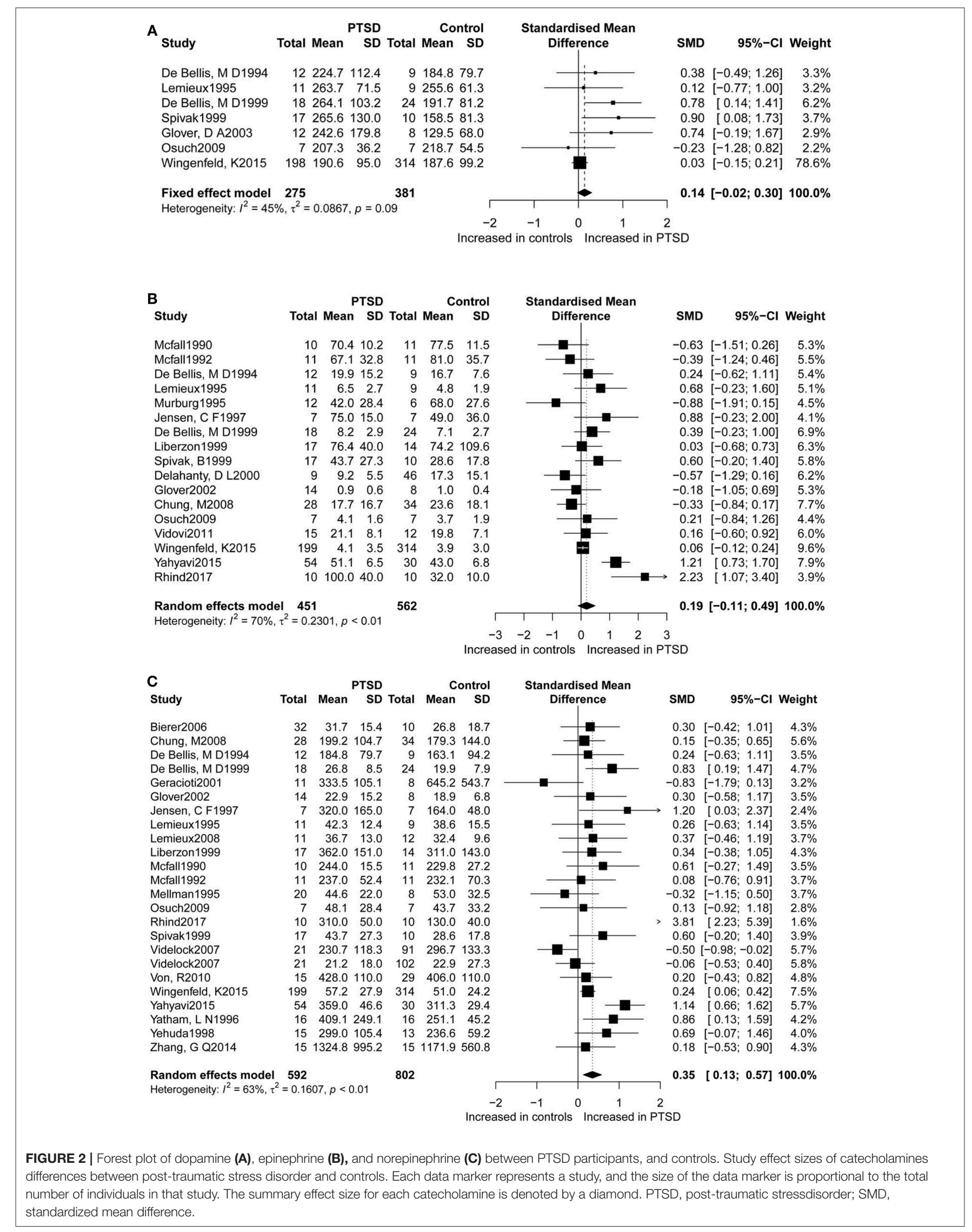




\section{Subgroup Analyses}

Subgroup analyses that assessed dopamine concentrations did not show any significant associations. Similarly, most subgroup analyses comparing epinephrine concentrations between participants with PTSD and the controls led to non-significant differences. Trauma type explained all model heterogeneity with no significant residual heterogeneity $\left(I^{2}=0\right)$. On the other hand, sample type significantly explained a large amount of the heterogeneity, but residual heterogeneity $\left(I^{2}=11.5 \%\right)$ was still detected (Table 2 and Figure 3B). Non-significant differences between PTSD and controls were found in relation to gender of the study participants. Concentrations of norepinephrine were higher in urinary samples in participants with PTSD than in the controls (SMD ranging from 0.10 to $0.38, p=$ $0.001)$, with no heterogeneity $\left(I^{2}=0 \%\right)$. Additionally, for the norepinephrine studies conducted in the United States, the geographical differences significantly explained all heterogeneity (SMD ranging from 0.13 to $0.39, p<0.001, I^{2}=0 \%$ ). Nonsignificant differences between PTSD and the controls were found in the following subgroup analyses: studies conducted outside of the United States (SMD 0.60, 95\% CI-0.01 to $1.22 ; p$ $=0.056$ ), assayed method was HPLC (SMD 0.20,-0.01 to 0.39; $p=0.055)$, and studies without storing sample in cold (SMD $0.38,-0.03$ to $0.78 ; p=0.068$ ) (Table 2 and Figure 3C).

After analyzing the pooled data, we performed each analysis separately for data from plasma and urine if the requirements for subgroup analyses were met. Most of the results were similar to those of the subgroup analyses performed using pooled data (Table 3). Nevertheless, one subgroup analysis comparing epinephrine concentrations in urinary samples of PTSD patients to the controls led to a significant difference. Also, we observed significantly higher epinephrine concentrations in PTSD patients compared to the controls (SMD 0.51, 95\% CI-0.02 to $1.00 ; p=0.043)$, with no heterogeneity $\left(I^{2}=\right.$ $0 \%)$. when PTSD was diagnosed using DSM-IV. Additionally, for the epinephrine concentrations in PTSD patients compared to the non-trauma-exposed controls, the types of controls used explained all heterogeneity $\left(I^{2}=0 \%\right)$. We also observed significantly higher urinary norepinephrine concentrations in PTSD patients with non-combat trauma compared to the controls (SMD $0.25,95 \%$ CI 0.10 to $0.40 ; p=0.001$ ), with no heterogeneity $\left(I^{2}=0 \%\right)$. However, no significant differences between combat trauma-exposed PTSD patients and the controls were observed. Similarly, we observed significantly higher urinary norepinephrine concentrations in PTSD patients compared to non-trauma-exposed controls (SMD 0.30, 95\% CI 0.08 to $0.53 ; p=0.001$ ), but no significant differences between PTSD patients and trauma-exposed controls.

\section{Sensitivity and Bias Analysis}

Sensitivity analysis indicated that any single study or a cluster of studies sharing some characteristics had a small influence on the SMD and the corresponding 95\% CI. Publication bias was not reported for dopamine because the number of studies reporting dopamine was $<10$ for each comparison (Table 2 and Figure 3A) No obvious asymmetry was observed in the shape of the funnel plot, and the Egger's test scored a $p$-value of 0.626 and
0.282 for epinephrine and norepinephrine, respectively, implying the lack of publication bias for studies on these two biomarkers.

\section{DISCUSSION}

To the best of our knowledge, this is the first systematic review and meta-analysis to explore the relationship between the PTSD status and levels of catecholamines (dopamine, epinephrine, and norepinephrine) in the plasma and/or urine. The findings suggest no association of dopamine or epinephrine concentrations with PTSD. However, norepinephrine levels were higher in PTSD patients than in controls. Nonetheless, the heterogeneity was considerably high, indicating that differences between subgroups might be present. Contrary to a previous study (Lee et al., 2017), this meta-analysis did not reveal a significant difference in dopamine concentrations between PTSD participants and controls. For epinephrine, this meta-analysis showed higher concentrations in PTSD individuals than in the controls, which however were not significant. Therefore, more studies are needed to assess if dopamine or epinephrine are truly associated with PTSD (Yahyavi et al., 2015).

In contrast, PTSD patients had significantly higher norepinephrine levels than controls, which is in line with previous hypothesis that predicted an association of norepinephrine with PTSD (Rebecca and Hendrickson, 2016).

It should be noted that in this meta-analysis data of plasma and urine concentrations were pooled for comparing PTSD cases and controls. While this may increase the power of statistical analyses, from a biological point of view, this approach may be limited by potential confounding factors in different types of samples (Dikanovic et al., 2011). Thus, after completing analyses of pooled data, we also performed each analysis separately in data from plasma and urine. Moreover, studies reporting other comorbid mental disorders were excluded from this meta-analysis to focus on the relationship between the catecholamines and PTSD only, although an investigation on these studies could be important. Likewise, studies on catecholamine levels in CSF or metabolites of catecholamines could not be included in the analyses, because either the number of the studies containing this information was is not enough to perform the relevant analyses, or the studies containing this information did not meet eligibility criteria, e.g., they reported comorbidity between anxiety/depression and PTSD cases (Sher et al., 2005).

Although anxiety/depression and PTSD are often comorbid, there was considerable variation in the comorbidity rates of anxiety/depression and PTSD, which may be confounded by variables that were not measured in the population (Koenig et al., 2018; Malgaroli et al., 2018), e.g., the variation could be related to the presence or absence of disturbances in the HPA axis. Nevertheless, changes in catecholamine metabolism or abnormalities in monoaminergic transmitter may contribute to the comorbidity of depression with PTSD (Sher et al., 2005; Strawn et al., 2010). For example, depressed subjects with PTSD had higher homovanillic acid (HVA) levels than the depressed subjects without comorbid PTSD, although the 
TABLE 2 | Subgroup Analysis of dopamine, epinephrine and norepinephrine between PTSD participants and controls.

\begin{tabular}{|c|c|c|c|c|c|c|c|c|c|c|c|}
\hline & $N$ & SMD & \multicolumn{2}{|c|}{$(95 \% \mathrm{Cl})$} & $z$ & $\boldsymbol{P}$ & \multicolumn{5}{|c|}{ Heterogeneity } \\
\hline All & 7 & 0.14 & -0.02 & 0.30 & 1.71 & 0.088 & 11.00 & 6 & 0.0884 & 0.0867 & $45.50 \%$ \\
\hline \multicolumn{12}{|c|}{ Controls type } \\
\hline TC & 3 & 0.24 & -0.31 & 0.78 & 0.85 & 0.396 & 1.94 & 2 & 0.3782 & 0.0000 & $0.00 \%$ \\
\hline DSM-IV & 4 & 0.30 & -0.18 & 0.78 & 1.24 & 0.216 & 7.15 & 3 & 0.0673 & 0.1306 & $58.00 \%$ \\
\hline Other & 3 & 0.49 & -0.01 & 0.98 & 1.93 & 0.054 & 1.72 & 2 & 0.4229 & 0.0000 & $0.00 \%$ \\
\hline \multicolumn{12}{|l|}{ Frozen } \\
\hline Yes & 4 & 0.45 & -0.06 & 0.95 & 1.74 & 0.081 & 8.92 & 3 & 0.0304 & 0.1622 & $66.40 \%$ \\
\hline No & 3 & 0.24 & -0.31 & 0.78 & 0.85 & 0.396 & 1.94 & 2 & 0.3782 & 0.0000 & $0.00 \%$ \\
\hline Plasma & 9 & 0.23 & -0.37 & 0.82 & 0.75 & 0.453 & 43.71 & 8 & $<0.0001$ & 0.647 & $81.70 \%$ \\
\hline \multicolumn{12}{|c|}{ Study country } \\
\hline USA & 12 & 0.00 & -0.14 & 0.14 & 0.03 & 0.980 & 16.60 & 11 & 0.1201 & 0.049 & $33.80 \%$ \\
\hline Not USA & 5 & 0.85 & 0.22 & 1.48 & 2.63 & 0.009 & 12.39 & 4 & 0.0147 & 0.337 & $67.70 \%$ \\
\hline \multicolumn{12}{|c|}{ Trauma type } \\
\hline Combat & 11 & 0.30 & -0.20 & 0.80 & 1.18 & 0.238 & 45.06 & 10 & $<0.0001$ & 0.527 & $77.80 \%$ \\
\hline Other & 6 & 0.06 & -0.10 & 0.21 & 0.68 & 0.497 & 4.51 & 5 & 0.4782 & 0.000 & $0.00 \%$ \\
\hline \multicolumn{12}{|l|}{ Gender } \\
\hline Female & 8 & 0.09 & -0.07 & 0.24 & 1.13 & 0.260 & 8.27 & 7 & 0.3095 & 0.019 & $15.30 \%$ \\
\hline Male & 9 & 0.21 & -0.37 & 0.78 & 0.71 & 0.478 & 43.21 & 8 & $<0.0001$ & 0.605 & $81.50 \%$ \\
\hline HPLC & 9 & 0.06 & -0.08 & 0.21 & 0.82 & 0.412 & 10.04 & 8 & 0.2622 & 0.021 & $20.30 \%$ \\
\hline Other & 8 & 0.30 & -0.40 & 1.00 & 0.84 & 0.401 & 37.20 & 7 & $<0.0001$ & 0.802 & $81.20 \%$ \\
\hline Frozen & & & & & & & & & & & \\
\hline Yes & 11 & 0.06 & -0.29 & 0.41 & 0.34 & 0.736 & 33.95 & 10 & 0.0002 & 0.211 & $70.50 \%$ \\
\hline No & 6 & 0.55 & -0.13 & 1.23 & 1.58 & 0.114 & 18.38 & 5 & 0.0025 & 0.501 & $72.80 \%$ \\
\hline Norepine & & & & & & & & & & & \\
\hline All & 24 & 0.35 & 0.13 & 0.57 & 3.12 & 0.002 & 61.90 & 23 & $<0.0001$ & 0.161 & $62.80 \%$ \\
\hline Sample & & & & & & & & & & & \\
\hline Urinary & 11 & 0.24 & 0.10 & 0.38 & 3.35 & 0.001 & 7.64 & 10 & 0.6644 & 0.000 & $0.00 \%$ \\
\hline Plasma & 13 & 0.48 & 0.06 & 0.90 & 2.24 & 0.025 & 53.25 & 12 & $<0.0001$ & 0.433 & $77.50 \%$ \\
\hline Study col & & & & & & & & & & & \\
\hline USA & 16 & 0.26 & 0.13 & 0.39 & 3.91 & $\varangle 0.0001$ & 14.84 & 15 & 0.4632 & 0.000 & $0.00 \%$ \\
\hline Not USA & 8 & 0.60 & -0.01 & 1.22 & 1.91 & 0.056 & 46.60 & 7 & $<0.0001$ & 0.627 & $85.00 \%$ \\
\hline Trauma $t y$ & & & & & & & & & & & \\
\hline Combat & 13 & 0.55 & 0.15 & 0.95 & 2.67 & 0.008 & 40.86 & 12 & $<0.0001$ & 0.364 & $70.60 \%$ \\
\hline Other & 11 & 0.18 & 0.05 & 0.32 & 2.65 & 0.008 & 13.63 & 10 & 0.1906 & 0.027 & $26.60 \%$ \\
\hline Gender & & & & & & & & & & & \\
\hline Female & 14 & 0.22 & 0.09 & 0.35 & 3.28 & 0.001 & 19.58 & 13 & 0.1061 & 0.043 & $33.60 \%$ \\
\hline Male & 10 & 0.50 & 0.01 & 1.00 & 2.00 & 0.046 & 38.31 & 9 & $<0.0001$ & 0.461 & $76.50 \%$ \\
\hline
\end{tabular}




\begin{tabular}{|c|c|c|c|c|c|c|c|c|c|c|c|}
\hline & $N$ & SMD & \multicolumn{2}{|c|}{$(95 \% \mathrm{Cl})$} & $z$ & $P$ & \multicolumn{5}{|c|}{ Heterogeneity } \\
\hline TC & 14 & 0.42 & 0.05 & 0.80 & 2.22 & 0.026 & 47.14 & 13 & $<0.0001$ & 0.341 & $72.40 \%$ \\
\hline NTC & 10 & 0.28 & 0.13 & 0.42 & 3.79 & 0.000 & 14.72 & 9 & 0.0988 & 0.055 & $38.90 \%$ \\
\hline \multicolumn{12}{|c|}{ PTSD assessment } \\
\hline Other & 12 & 0.35 & 0.11 & 0.59 & 2.82 & 0.005 & 14.32 & 11 & 0.2159 & 0.055 & $23.20 \%$ \\
\hline \multicolumn{12}{|c|}{ Assayed methods } \\
\hline HPLC & 16 & 0.20 & -0.01 & 0.39 & 1.92 & 0.055 & 25.54 & 15 & 0.0432 & 0.057 & $41.30 \%$ \\
\hline Other & 8 & 0.78 & 0.22 & 1.34 & 2.71 & 0.007 & 24.81 & 7 & 0.0008 & 0.447 & $71.80 \%$ \\
\hline \multicolumn{12}{|l|}{ Frozen } \\
\hline
\end{tabular}

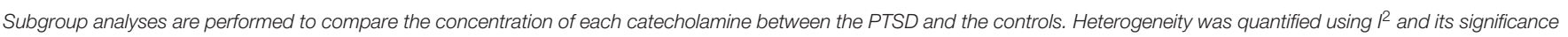

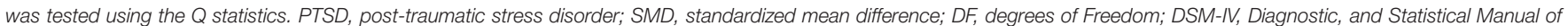

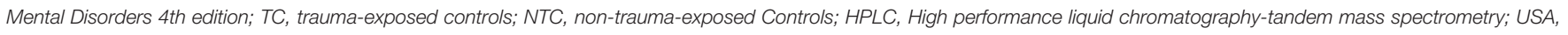
United States of America.

two groups did not differ in 5-hydroxyindolacetic acid (5HIAA) and 3-methoxy-4-hydroxyphenylglycol (MHPG) levels (Sher et al., 2005). In addition, studies on patients with substance use disorder (SUD) were excluded from this metaanalysis, because they may have taken a variety of substances or received medication that can affect catecholamine release and/or metabolism (Bountress et al., 2017).

Although males generally have a higher risk of experiencing trauma than females, females are twice more likely to develop PTSD than males (Gill et al., 2005). Current studies of individuals with PTSD provide evidence for alterations in the neuroendocrine system, e.g., catecholamines are affected by sex steroid hormones (Bangasser et al., 2018; Cao et al., 2018). In general, women appear to have a more sensitized HPA axis than men, and our findings indicated that females with PTSD showed higher concentrations of norepinephrine than female controls (Bangasser et al., 2016). Such differences were also apparent between males with PTSD and male controls, but with higher heterogeneity. This may explain why women are more vulnerable than men to the development of post-trauma symptoms and take longer than men to recover from them. Moreover, gender-specific psychobiological reactions (particularly of norepinephrine) to trauma may contribute to sex differences for a higher PTSD risk. For example, estrogen can increase norepinephrine in the target regions of the locus coeruleus by enhancing the capacity for norepinephrine synthesis, while reducing norepinephrine degradation, potentially increasing arousal in females (Bangasser et al., 2016). This effect could translate into hyperarousal in women under conditions of norepinephrine hypersecretion that occur in PTSD (Bangasser et al., 2013). However, it is noteworthy that the incidence of various types of trauma is generally also disproportionate between males and females, hence further investigations for confounding factors are necessary (Farhood et al., 2018).

\section{Subgroup Analyses}

Significantly high heterogeneity existed when assessing the relationship of catecholamines with PTSD, suggesting that there might have been some unmeasured moderators. With regard to dopamine, subgroup analyses indicated that the type of controls, PTSD assessment tools and use of refrigeration to preserve samples significantly explained heterogeneity with no significant residual heterogeneity. Also, subgroup analyses for epinephrine indicated that PTSD patients had significantly higher epinephrine concentrations than the controls in countries other than the United States. This result may suggest that different countries or regions may form different homogenous groups when investigating the relationship between catecholamines and PTSD. However, since more studies for this systematic review and meta-analysis were conducted in the United States, more future investigations are needed in other countries to verify this hypothesis Unfortunately, heterogeneity resulting from social political, economic, ethnic and cultural factors, and the level of technical experience could not be evaluated, because these characteristics were rarely reported in the eligible studies. Thus, we considered country of study as a likely substitute because it contains all those characteristics. Nonetheless, since most of the studies were conducted in the United States, grouping according to individual countries would not be very meaningful because other countries had relatively few publications on this topic. Thus, we grouped the studies as "studies conducted in the USA" and "studies conducted in other countries." This grouping formed the categories of the subgroup "country of study" in this investigation. Additionally, for epinephrine, trauma type explained all model heterogeneity with no significant residual heterogeneity. It is difficult to explain this result, but it might suggest that differences in epinephrine concentrations were related to being exposed to trauma in general rather than manifestation of PTSD (Eiden, 2013). Findings of the current study suggest the need to consider 

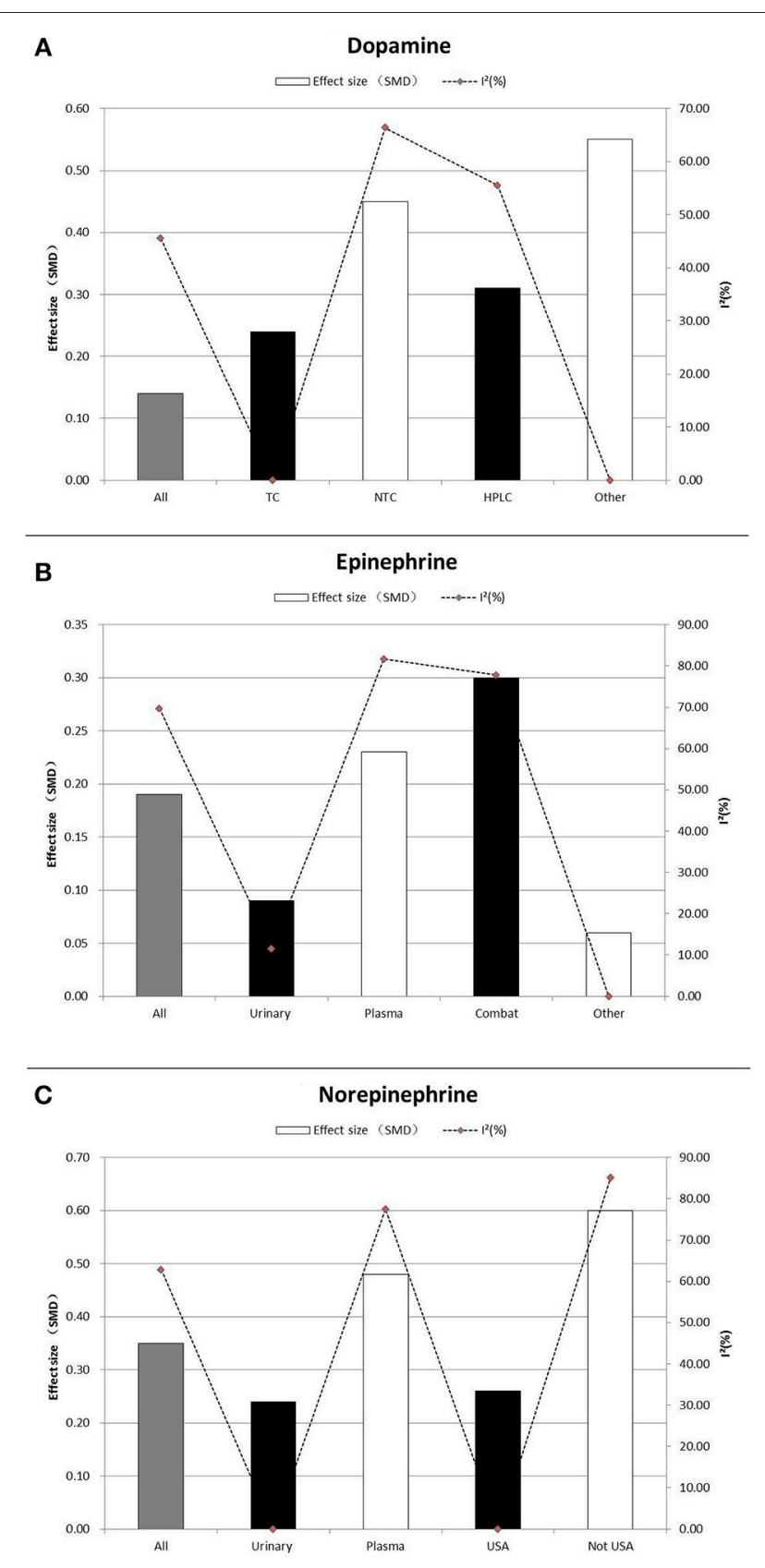

FIGURE 3 | Subgroup Analysis of dopamine (A), epinephrine (B), and norepinephrine (C) between PTSD participants, and controls. Study effect sizes of catecholamines differences between post-traumatic stress disorder and controls in the subgroups. Each histogram represents a subgroup, and the height of the histogram is proportional to the total effect size of subgroup in that study. The heterogeneity $\left(I^{2}\right)$ for each subgroup is denoted by a dot with dotted line. SMD, standardized mean difference; TC, trauma-exposed controls; NTC, non-trauma-exposed Controls; HPLC, High performance liquid chromatography-tandem mass spectrometry; USA, United States of America.

trauma type as an important factor of PTSD (Hodgdon et al., 2018). In agreement with this suggestion, Guina, J et al found that combat trauma was associated with total PTSD severity, arousal and intrusions (especially physical symptoms) (Guina et al., 2018). However, non-combat trauma was associated with conscious avoidance and negative cognitions/mood. To date the biological mechanisms underlying these risk factors remain poorly understood (Guina et al., 2018). According to these results, it may well be that trauma type affects the output of epinephrine in PTSD. Moreover, further studies will be needed to explore potential pharmacological mechanisms or the relationship between epinephrine and PTSD symptoms. Furthermore, sample types significantly explained a large amount of the heterogeneity, but residual heterogeneity was still detected $\left(I^{2}=11.5 \%\right)$. It is known that the epinephrine release follows a circadian rhythm. In this regard sample type (urine or plasma) might influence the results (Glover and Poland, 2002).

Results showed that norepinephrine concentrations were higher in urinary samples in participants with PTSD than in controls, with no heterogeneity. This may imply that in future studies urinary samples should be preferred for norepinephrine testing (Bandelow et al., 2017).

For studies on norepinephrine conducted in the United States, no heterogeneity was detected (SMD ranging from 0.13 to $0.39, p$ $\left.<0.001, I^{2}=0 \%\right)$. This may suggests that the United States had a relatively stable infrastructure for testing norepinephrine levels resulting in reliable outcomes (Rebecca and Hendrickson, 2016).

After analysis of the pooled data, we performed each analysis separately for data from plasma and urine (Table 3). However, the random effect model incorporates the estimate of the between study variance to calculate the pooled SMD, and this estimate is more prone to error when the study included in subgroup analyses were $<2$ (Higgins et al., 2009). Thus, some studies failed to be included in subgroup analyses. Contrary to the outcomes of subgroup analyses discussed above, we observed significantly higher epinephrine concentrations in PTSD patients which were diagnosed by DSM-IV, compared to controls. This result may indicate that the diagnostic tools may account for the different results of subgroup analyses, and DSM-IV may produce consistent results when used in different study populations. Thus, compared with other scales and diagnostic criteria, we recommend the use of DSM diagnostic criteria (Schnyder et al., 2015). This criterion has proved to show a high degree of reliability and validity, and can provide a better reference for further studies on PTSD and catecholamines (Hansen et al., 2017).

Also, in this study, significantly higher urinary norepinephrine concentrations were observed in PTSD patients compared to non-trauma-exposed controls, but no significant differences between PTSD patients and trauma-exposed controls were observed. Therefore, exposure to traumatic events may affect norepinephrine levels, without additional independent effects of PTSD. The neurobiological pathways of norepinephrine in acute stress disorder were well-described (Thoma et al., 2012). But the exact biological mechanisms underlying the altered longterm norepinephrine output as a result of trauma remain largely unknown (Beis et al., 2018). Speculatively, increased output after trauma may evolve as a compensatory anti-glucocorticoid mechanism, to inhibit negative effects of a long-term increase in negative glucocorticoid feedback and sensitivity of glucocorticoid receptors that has been observed in trauma-exposed participants 
TABLE 3 | Subgroup Analysis of epinephrine and norepinephrine in urinary and plasma between PTSD participants and controls.

\begin{tabular}{|c|c|c|c|c|c|c|c|c|c|c|c|}
\hline & \multirow[t]{2}{*}{$\mathbf{N}$} & \multirow[t]{2}{*}{ SMD } & \multicolumn{2}{|c|}{$(95 \% \mathrm{Cl})$} & \multirow[t]{2}{*}{$\mathbf{Z}$} & \multirow[t]{2}{*}{$P$-value } & \multicolumn{5}{|c|}{ Heterogeneity } \\
\hline & & & & & & & Q statistic & (DF & $p$-value) & $\tau^{2}$ & $I^{2}$ \\
\hline \multicolumn{12}{|c|}{ EPINEPHRINE-URINARY } \\
\hline \multicolumn{12}{|c|}{ Controls type } \\
\hline NTC & 3 & 0.23 & -0.31 & 0.77 & 0.83 & 0.409 & 1.80 & 2 & 0.4062 & 0.000 & $0.00 \%$ \\
\hline TC & 5 & 0.08 & -0.08 & 0.24 & 0.99 & 0.320 & 5.84 & 4 & 0.2111 & 0.037 & $31.60 \%$ \\
\hline \multicolumn{12}{|c|}{ PTSD assessment } \\
\hline DSM-IV & 5 & 0.51 & 0.02 & 1.00 & 2.02 & 0.043 & 0.55 & 4 & 0.7589 & 0.000 & $0.00 \%$ \\
\hline Other & 3 & 0.05 & -0.11 & 0.21 & 0.59 & 0.556 & 4.32 & 2 & 0.3640 & 0.007 & $7.50 \%$ \\
\hline \multicolumn{12}{|c|}{ EPINEPHRINE-PLASMA } \\
\hline \multicolumn{12}{|c|}{ Controls type } \\
\hline TC & 6 & 0.52 & -0.28 & 1.32 & 1.28 & 0.199 & 29.15 & 5 & $<0.0001$ & 0.795 & $82.80 \%$ \\
\hline NTC & 3 & -0.28 & -0.76 & 0.19 & -1.17 & 0.240 & 2.65 & 2 & 0.2660 & 0.046 & $24.50 \%$ \\
\hline \multicolumn{12}{|c|}{ PTSD ASSESSMENT } \\
\hline DSM-IV & 4 & 0.75 & -0.26 & 1.75 & 1.46 & 0.146 & 28.00 & 3 & $<0.0001$ & 0.907 & $89.30 \%$ \\
\hline Other & 5 & -0.22 & -0.74 & 0.30 & -0.83 & 0.409 & 6.75 & 4 & 0.1497 & 0.143 & $40.70 \%$ \\
\hline \multicolumn{12}{|c|}{ ASSAYED METHODS } \\
\hline HPLC & 3 & -0.13 & -0.49 & 0.23 & -0.69 & 0.490 & 1.39 & 2 & 0.4993 & 0.000 & $0.00 \%$ \\
\hline Other & 6 & 0.39 & -0.53 & 1.32 & 0.83 & 0.405 & 34.48 & 5 & $<0.0001$ & 1.114 & $85.50 \%$ \\
\hline \multicolumn{12}{|c|}{ NOREPINEPHRINE-URINARY } \\
\hline \multicolumn{12}{|c|}{ Study country } \\
\hline USA & 8 & 0.26 & 0.11 & 0.42 & 3.39 & 0.001 & 5.09 & 7 & 0.6486 & 0.000 & $0.00 \%$ \\
\hline Not USA & 3 & 0.11 & -0.27 & 0.49 & 0.57 & 0.570 & 1.99 & 2 & 0.3699 & 0.000 & $0.00 \%$ \\
\hline \multicolumn{12}{|c|}{ Trauma type } \\
\hline Combat & 3 & 0.18 & -0.36 & 0.72 & 0.66 & 0.509 & 2.52 & 2 & 0.2830 & 0.048 & $20.80 \%$ \\
\hline Other & 8 & 0.25 & 0.10 & 0.40 & 3.28 & 0.001 & 5.05 & 7 & 0.6540 & 0.000 & $0.00 \%$ \\
\hline \multicolumn{12}{|c|}{ Controls type } \\
\hline TC & 5 & 0.11 & -0.20 & 0.43 & 0.70 & 0.485 & 1.08 & 4 & 0.8974 & 0.000 & $0.00 \%$ \\
\hline NTC & 6 & 0.30 & 0.08 & 0.53 & 2.62 & 0.009 & 5.75 & 5 & 0.3317 & 0.013 & $13.00 \%$ \\
\hline \multicolumn{12}{|l|}{ Frozen } \\
\hline Yes & 6 & 0.30 & 0.07 & 0.52 & 2.59 & 0.010 & 5.70 & 5 & 0.3363 & 0.013 & $12.30 \%$ \\
\hline No & 5 & 0.13 & -0.19 & 0.44 & 0.78 & 0.434 & 1.26 & 4 & 0.8682 & 0.000 & $0.00 \%$ \\
\hline \multicolumn{12}{|c|}{ NOREPINEPHRINE-PLASMA } \\
\hline \multicolumn{12}{|c|}{ Trauma type } \\
\hline Combat & 10 & 0.67 & 0.18 & 1.16 & 2.68 & 0.007 & 35.93 & 9 & $<0.0001$ & 0.435 & $75.00 \%$ \\
\hline Other & 3 & -0.09 & -0.58 & 0.41 & -0.35 & 0.723 & 4.08 & 2 & 0.1299 & 0.098 & $51.00 \%$ \\
\hline \multicolumn{12}{|c|}{ Controls type } \\
\hline TC & 9 & 0.61 & 0.04 & 1.18 & 2.11 & 0.035 & 44.00 & 8 & $<0.0001$ & 0.584 & $81.80 \%$ \\
\hline NTC & 4 & 0.26 & -0.36 & 0.89 & 0.83 & 0.404 & 8.97 & 3 & 0.0297 & 0.262 & $66.60 \%$ \\
\hline \multicolumn{12}{|c|}{ Assayed methods } \\
\hline HPLC & 7 & 0.13 & -0.28 & 0.55 & 0.63 & 0.528 & 16.72 & 6 & 0.0104 & 0.192 & $64.10 \%$ \\
\hline Other & 6 & 0.98 & 0.26 & 1.71 & 2.66 & 0.008 & 22.10 & 5 & 0.0005 & 0.596 & $77.40 \%$ \\
\hline
\end{tabular}

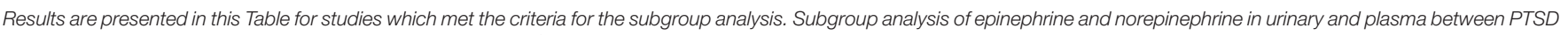

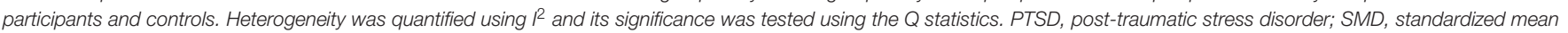

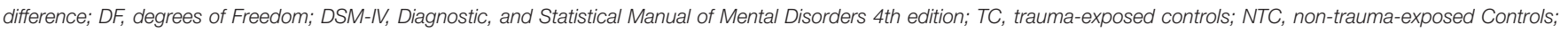
HPLC, High performance liquid chromatography-tandem mass spectrometry; USA, United States of America.

irrespective of PTSD status (Nawata et al., 1985; Zenko et al., 2018). However, this remains to be further investigated. This study also found that the type of sample affects heterogeneity in subgroup analyses. For example, heterogeneity in urine samples was significantly lower than that in plasma samples.
Especially for norepinephrine in plasma samples, results from the studies included in these subgroup comparisons were highly heterogeneous.

It is difficult to explain this result, but with regard to methodological aspects, due to the pulsatile nature of 
catecholamines release, there are inherent limitations when using single-point measurements of basal catecholamines levels (Nicolau et al., 1985; Kondo et al., 2002). More specifically, it is known that the timing of the measurements throughout the day is important as catecholamine release follows a circadian rhythm (Rao et al., 1995; James et al., 2014). Although most plasma samples studies reported the specific time of assessments, we cannot exclude that variation in assessment timing affected our results. Thus, the results should be interpreted cautiously. However, a possible explanation for this result is that the 24$\mathrm{h}$ urinary cortisol has been considered to provide an integrated measure that was more reliable and stable than plasma samples.

In spite of showing an association between some catecholamines and PTSD, this meta-analysis is subject to several limitations.

First, the meta-analysis for dopamine and epinephrine failed to achieve statistical significance. There was lack of power in these analyses, with may lead to a high degree of falsenegative results. Second, the literature used for this meta-analysis originated from cross-sectional studies, which could not make causality inference. Finally, some factors that may influence catecholamine concentrations such as BMI (body-mass index), smoking, drinking, physical activity, blood pressure, were not measured or adjusted in the original studies.

\section{CONCLUSION}

In conclusion, despite the above limitations, the results from our study provide a convincing evidence of the relationship between norepinephrine levels and PTSD. The evidence from this metaanalysis supports significantly higher norepinephrine levels in people with PTSD than in the controls, but no difference was

\section{REFERENCES}

Aubry, A. V., Serrano, P. A., and Burghardtl, N. S. (2016). Molecular mechanisms of stress-induced increases in fear memory consolidation within the amygdala. Front. Behav. Neurosci. 10: 191. doi: 10.3389/fnbeh.2016.00191

Bandelow, B., Baldwin, D., Abelli, M., Bolea-Alamanac, B., Bourin, M., Chamberlain, S. R. et al. (2017). Biological markers for anxiety disorders, OCD and PTSD: a consensus statement. part II: neurochemistry, neurophysiology and neurocognition. World J. Biol. Psychiatry 183, 162-214. doi: 10.1080/15622975.2016.1190867

Bangasser, D. A., Eck, S. R., and Ordones, S. E. (2018). Sex differences in stress reactivity in arousal and attention systems. Neuropsychopharmacology 44, 129-39. doi: 10.1038/s41386-018-0137-2

Bangasser, D. A., Reyes, B. A., Piel, D., Garachh, V., Zhang, X. Y., Plona, Z. M., et al. (2013). Increased vulnerability of the brain norepinephrine system of females to corticotropin-releasing factor overexpression. Mol. Psychiatry 182, 166-173. doi: $10.1038 / \mathrm{mp} .2012 .24$

Bangasser, D. A., Wiersielis, K. R., and Khantsis, S. (2016). Sex differences in the locus coeruleus-norepinephrine system and its regulation by stress. Brain Res. 1641, 177-188. doi: 10.1016/j.brainres.2015.11.021

Beis, D., von Kanel, R., Heimgartner, N., Zuccarella-Hackl, C., Burkle, A., Ehlert, U., et al. (2018). The role of norepinephrine and alpha-adrenergic receptors in acute stress-induced changes in granulocytes and monocytes. Psychosom. Med. 807, 649-658. doi: 10.1097/PSY.0000000000000620

Bierer, L. M., Tischler, L., Labinsky, E., Cahill, S., Foa, E., and Yehuda, R. (2006). Clinical correlates of 24 -h cortisol and norepinephrine excretion found in dopamine and epinephrine concentrations between the two groups. Elevated norepinephrine levels may be an important indicator for PTSD, although whether norepinephrine could be used as a diagnostic tool requires further research.

\section{AUTHOR CONTRIBUTIONS}

$\mathrm{XP}$ and $\mathrm{AL}$ contributed to the study design, while XP and AK contributed to the data collection. Statistical analyses and interpretation of results were performed by XP and AK, while $\mathrm{AL}$ and SW drafted the manuscript and edited the language. All the authors participated in the critical revision, and approved the final version of the manuscript.

\section{FUNDING}

This study was funded by the Canadian Institutes of Health Research (CIHR grant \# FDN-148438) and the Hunan Provincial Key Research and Development Program (2018SK2065).

\section{ACKNOWLEDGMENTS}

We are grateful to Central South University Library for the assistance during the literature search. Furthermore, we sincerely appreciate the hard work from the distinguished editors and reviewers.

\section{SUPPLEMENTARY MATERIAL}

The Supplementary Material for this article can be found online at: https://www.frontiersin.org/articles/10.3389/fnmol. 2018.00450/full\#supplementary-material among subjects seeking treatment following the World Trade Center attacks on 9/11. Ann. N. Y. Acad. Sci. 1071, 514-520. doi: 10.1196/annals. 1364.055

Bountress, K. E., Wei, W., Sheerin, C., Chung, D., Amstadter, A. B., Mandel, H., et al. (2017). Relationships between GAT1 and PTSD, depression, and substance use disorder. Brain Sci. 7:6. doi: 10.3390/brainsci7010006

Burstajn, H. J., and First, M. B. (2014). PTSD diagnoses can avoid avoidance as an absolute criterion. Lancet Psychiatry 15, 332-333. doi: 10.1016/S2215-0366(14)70362-1

Butterfield, M. I., Stechuchak, K. M., Connor, K. M., Davidson, J. R., Wang, C., MacKuen, C. L., et al. (2005). Neuroactive steroids and suicidality in posttraumatic stress disorder. Am. J. Psychiatry 1622, 380-382. doi: 10.1176/appi.ajp.162.2.380

Cao, X., Wang, L., Cao, C., Fang, R., Chen, C., Hall, B. J., et al. (2018). Sex differences in global and local connectivity of adolescent posttraumatic stress disorder symptoms. J. Child Psychol. Psychiatry. 12, 1229-1237. doi: $10.1111 /$ jcpp. 12963

Chung, M., Kim, T., and Chung, H. (2008). The change of biogenic amines and cortisol in posttraumatic stress disorder after long-term pharmacological treatment. Eur. Neuropsychopharm. 18, 479-497. doi: 10.1016/S0924-977X(08)70745-4

Cordova, M. J., Riba, M. B., and Spiegel, D. (2017). Post-traumatic stress disorder and cancer. Lancet Psychiatry 44, 330-338. doi: 10.1016/S2215-0366(17)30014-7

De Bellis, M. D., Baum, A. S., Birmaher, B., Keshavan, M. S., Eccard, C. H., Boring, A. M, et al. (1999). Developmental traumatology 
Part I: biological stress systems. Biol. Psychiatry 4510, 1259-1270. doi: 10.1016/S0006-3223(99)00044-X

De Bellis, M. D., Lefter, L., Trickett, P. K., and Putnam, F. W. J. (1994). Urinary catecholamine excretion in sexually abused girls. J. Am. Acad. Child Adolesc. Psychiatry 333, 320-327. doi: 10.1097/00004583-199403000-00004

Delahanty, D. L., Raimonde, A. J., and Spoonster, E. (2000). Initial posttraumatic urinary cortisol levels predict subsequent PTSD symptoms in motor vehicle accident victims. Biol. Psychiatry 489, 940-947. doi: 10.1016/S0006-3223(00)00896-9

Dikanovic, M., Demarin, V., Kadojic, D., Kadojic, M., Trkanjec, Z., Titlic, M., et al. (2011). Effect of elevated catecholamine levels on cerebral hemodynamics in patients with chronic post-traumatic stress disorder. Coll. Antropol. 352, $471-475$.

Egger, M., Davey, S. G., Schneider, M., and Minder, C. (1997). Bias in meta-analysis detected by a simple, graphical test. BMJ 3157109, 629-634.

Eiden, L. E. (2013). Neuropeptide-catecholamine interactions in stress. $A d v$. Pharmacol. 68, 399-404. doi: 10.1016/B978-0-12-411512-5.00018-X

Farhood, L., Fares, S., and Hamady, C. (2018). PTSD and gender: could gender differences in war trauma types, symptom clusters and risk factors predict gender differences in PTSD prevalence? Arch. Womens Ment. Health 21, 725-733. doi: 10.1007/s00737-018-0849-7

Geracioti, T. J., Baker, D. G., Kasckow, J. W., Strawn, J. R., Jeffrey, M. J., Dashevsky, B. A., et al. (2008). Effects of trauma-related audiovisual stimulation on cerebrospinal fluid norepinephrine and corticotropin-releasing hormone concentrations in post-traumatic stress disorder. Psychoneuroendocrinology 334, 416-424. doi: 10.1016/j.psyneuen.2007.12.012

Gill, J. M., Szanton, S. L., and Page, G. G. (2005). Biological underpinnings of health alterations in women with PTSD: a sex disparity. Biol. Res. Nurs. 71, 44-54. doi: 10.1177/1099800405276709

Glover, D. A., and Poland, R. E. (2002). Urinary cortisol and catecholamines in mothers of child cancer survivors with and without PTSD. Psychoneuroendocrinology 277, 805-819. doi: 10.1016/S0306-4530(01)00081-6

Glover, D. A., Powers, M. B., Bergman, L., Smits, J. A. J., Telch, M. J., and Stuber, M. (2003). Urinary dopamine and turn bias in traumatized women with and without PTSD symptoms. Behav. Brain Res. 144, 137-141. doi: 10.1016/S0166-4328(03)00074-3

Gold, M. S., Blum, K., Febo, M., Baron, D., Modestino, E. J., Elman, I., et al. (2018). Molecular role of dopamine in anhedonia linked to reward deficiency syndrome (RDS) and anti-reward systems. Front. Biosci. (Schol Ed). 10, 309-325. doi: 10.2741/s518

Guina, J., Nahhas, R. W., Sutton, P., and Farnsworth, S. (2018). The influence of trauma type and timing on PTSD symptoms. J. Nerv. Ment. Dis. 206, 72-76. doi: 10.1097/NMD.0000000000000730

Hansen, M., Hyland, P., Karstoft, K. I., Vaegter, H. B., Bramsen, R. H., Nielsen, A., et al. (2017). Does size really matter? A multisite study assessing the latent structure of the proposed ICD-11 and DSM-5 diagnostic criteria for PTSD. Eur. J. Psychotraumatol. 8 (Suppl. 7):1398002. doi: 10.1080/20008198.2017. 1398002

Hardy, K. V., and Mueser, K. T. (2017). Editorial: trauma, psychosis and posttraumatic stress disorder. Front. Psychiatry 8:220.doi: 10.3389/fpsyt.2017.00220

Hauer, D., Kaufmann, I., Strewe, C., Briegel, I., Campolongo, P., and Schelling, G. (2014). The role of glucocorticoids, catecholamines and endocannabinoids in the development of traumatic memories and posttraumatic stress symptoms in survivors of critical illness. Neurobiol. Learn. Mem. 112, 68-74. doi: 10.1016/j.nlm.2013.10.003

Higgins, J. P., Thompson, S. G., Deeks, J. J., and Altman, D. G. (2003). Measuring inconsistency in meta-analyses. BMJ 327, 557-560. doi: $10.1136 / \mathrm{bmj} .327 .7414 .557$

Higgins, J. P., Thompson, S. G., and Spiegelhalter, D. J. (2009). A re-evaluation of random-effects meta-analysis. J. R. Stat. Soc. Ser. A Stat. Soc. 1721, 137-159. doi: 10.1111/j.1467-985X.2008.00552.x

Highland, K. B., Costanzo, M. E., Jovanovic, T., Norrholm, S. D., Ndiongue, R. B., Reinhardt, B. J., et al. (2015). Catecholamine responses to virtual combat: implications for post-traumatic stress and dimensions of functioning. Front. Psychol. 6:256. doi: 10.3389/fpsyg.2015.00256

Hodgdon, H. B., Liebman, R., Martin, L., Suvak, M., Beserra, K., Rosenblum, W., et al. (2018). The effects of trauma type and executive dysfunction on symptom expression of polyvictimized youth in residential care. J. Trauma Stress 312, 255-264. doi: 10.1002/jts.22267

Hyland, P., Shevlin, M., Fyvie, C., and Karatzias, T. (2018). Posttraumatic stress disorder and complex posttraumatic stress disorder in DSM-5 and ICD-11: clinical and behavioral correlates. J. Trauma Stress 31, 174-180. doi: $10.1002 /$ jts. 22272

James, G. D., Alfarano, A. S., and van Berge-Landry, H. M. (2014). Differential circadian catecholamine and cortisol responses between healthy women with and without a parental history of hypertension. Am. J. Hum. Biol. 266, 753-759. doi: 10.1002/ajhb.22586

Jensen, C. F., Keller, T. W., Peskind, E. R., McFall, M. E., Veith, R. C., Martin, D., et al. (1997). Behavioral and neuroendocrine responses to sodium lactate infusion in subjects with posttraumatic stress disorder. Am. J. Psychiatry 1542, 266-268. doi: 10.1176/ajp.154.2.266

Johnson, L. R., Hou, M., Prager, E. M., and LeDoux, J. E. (2011). Regulation of the fear network by mediators of stress: norepinephrine alters the balance between cortical and subcortical afferent excitation of the lateral amygdala. Front. Behav. Neurosci. 5:23. doi: 10.3389/fnbeh.2011.00023

Kao, C. Y., Stalla, G., Stalla, J., Wotjak, C. T., and Anderzhanova, E. (2015). Norepinephrine and corticosterone in the medial prefrontal cortex and hippocampus predict PTSD-like symptoms in mice. Eur. J. Neurosci. 419, 1139-1148. doi: 10.1111/ejn.12860

Koenig, H. G., Youssef, N. A., Oliver, R., Ames, D., Haynes, K., Volk, F., et al. (2018). Religious involvement, anxiety/depression, and PTSD symptoms in US veterans and active duty military. J. Relig. Health 57, 2325-2342. doi: 10.1007/s10943-018-0692-1

Kondo, K., Matsubara, T., Nakamura, J., and Hotta, N. (2002). Characteristic patterns of circadian variation in plasma catecholamine levels, blood pressure and heart rate variability in Type 2 diabetic patients. Diabet. Med. 195, 359-365. doi: 10.1046/j.1464-5491.2002.00720.x

Lee, J. C., Wang, L. P., and Tsien, J. Z. (2016). Dopamine reboundexcitation theory: putting brakes on PTSD. Front. Psychiatry 7:163.doi: 10.3389/fpsyt.2016.00163

Lee, J. H., Lee, S., and Kim, J. (2017). Amygdala circuits for fear memory: a key role for dopamine regulation. Neuroscientist 235, 542-553. doi: 10.1177/1073858416679936

Lemieux, A., Coe, C. L., and Carnes, M. (2008). Symptom severity predicts degree of $\mathrm{T}$ cell activation in adult women following childhood maltreatment. Brain Behav. Immun. 226, 994-1003. doi: 10.1016/j.bbi.2008.02.005

Lemieux, A. M., and Coe, C. L. (1995). Abuse-related posttraumatic stress disorder: evidence for chronic neuroendocrine activation in women. Psychosom. Med. $572,105-115$.

Liberzon, I., Abelson, J. L., Flagel, S. B., Raz, J., and Young, E. A. (1999). Neuroendocrine and psychophysiologic responses in PTSD: a symptom provocation study. Neuropsychopharmacology 211, 40-50. doi: 10.1016/S0893-133X(98)00128-6

Malgaroli, M., Maccallum, F., and Bonanno, G. A. (2018). Symptoms of persistent complex bereavement disorder, depression, and PTSD in a conjugally bereaved sample: a network analysis. Psychol. Med. 48, 2439-2448. doi: 10.1017/S0033291718001769

Matthews, A. R., He, O. H., Buhusi, M., and Buhusi, C. V. (2012). Dissociation of the role of the prelimbic cortex in interval timing and resource allocation: beneficial effect of norepinephrine and dopamine reuptake inhibitor nomifensine on anxiety-inducing distraction. Front. Integr. Neurosci. 6:111. doi: 10.3389/fnint.2012.00111

McFall, M. E., Murburg, M. M., Ko, G. N., and Veith, R. C. (1990). Autonomic responses to stress in Vietnam combat veterans with posttraumatic stress disorder. Biol. Psychiatry 2710, 1165-1175. doi: 10.1016/0006-3223(90)90053-5

McFall, M. E., Veith, R. C., and Murburg, M. M. (1992). Basal sympathoadrenal function in posttraumatic distress disorder. Biol. Psychiatry 3110, 1050-1056. doi: 10.1016/0006-3223(92)90097-J

McFarlane, A. C. (2014). PTSD and DSM-5: unintended consequences of change. Lancet Psychiatry 14, 246-247. doi: 10.1016/S2215-0366(14)70321-9

McLaughlin, T., Blum, K., Oscar-Berman, M., Febo, M., Agan, G., Fratantonio, J. L., et al. (2015). Putative dopamine agonist (KB220Z) attenuates lucid nightmares in PTSD patients: role of enhanced brain reward functional connectivity and homeostasis redeeming joy. J. Behav. Addict. 42, 106-115. doi: $10.1556 / 2006.4 .2015 .008$ 
Mellman, T. A., Kumar, A., Kulick-Bell, R., Kumar, M., and Nolan, B. (1995). Nocturnal/daytime urine noradrenergic measures and sleep in combat-related PTSD. Biol. Psychiatry 383, 174-179. doi: 10.1016/0006-3223(94)00238-X

Mendoza, C., Barreto, G. E., Avila-Rodriguez, M., and Echeverria, V. (2016). Role of neuroinflammation and sex hormones in war-related PTSD. Mol. Cell Endocrinol. 434, 266-277. doi: 10.1016/j.mce.2016.05.016

Moher, D., Liberati, A., Tetzlaff, J., and Altman, D. G. (2010). Preferred reporting items for systematic reviews and meta-analyses: the PRISMA statement. Int. J. Surg. 85, 336-341. doi: 10.1016/j.ijsu.2010.02.007

Murburg, M. M., McFall, M. E., Lewis, N., and Veith, R. C. (1995). Plasma norepinephrine kinetics in patients with posttraumatic stress disorder. Biol. Psychiatry 3812, 819-825. doi: 10.1016/0006-3223(95)00044-5

Murphy, S., Elklit, A., Chen, Y. Y., Ghazali, S. R., and Shevlin, M. (2018). Sex differences in PTSD symptoms: a differential item functioning approach. Psychol. Trauma. 10, 67-75. doi: 10.1037/tra0000355

Nawata, H., Yanase, T., Higuchi, K., Kato, K., and Ibayashi, H. (1985). Epinephrine and norepinephrine syntheses are regulated by a glucocorticoid receptormediated mechanism in the bovine adrenal medulla. Life Sci. 3620, 1957-1966.

Nicolau, G. Y., Haus, E., Lakatua, D., Sackett-Lundeen, L., Bogdan, C., Plinga, L., et al. (1985). Differences in the circadian rhythm parameters of urinary free epinephrine, norepinephrine and dopamine between children and elderly subjects. Endocrinologie 233, 189-199.

Norrholm, S. D., Jovanovic, T., Smith, A. K., Binder, E., Klengel, T., Conneely, K., et al. (2013). Differential genetic and epigenetic regulation of catechol-Omethyltransferase is associated with impaired fear inhibition in posttraumatic stress disorder. Front. Behav. Neurosci. 7:30. doi: 10.3389/fnbeh.2013.00030

O’Donnell, T., Hegadoren, K. M., and Coupland, N. C. (2004). Noradrenergic mechanisms in the pathophysiology of post-traumatic stress disorder. Neuropsychobiology 50, 273-283. doi: 10.1159/000080952

Olff, M., and van Zuiden, M. (2017). Neuroendocrine and neuroimmune markers in PTSD: pre-, peri- and post-trauma glucocorticoid and inflammatory dysregulation. Curr. Opin. Psychol. 14, 132-137. doi: 10.1016/j.copsyc.2017.01.001

Onton, J. A., Matthews, S. C., Kang, D. Y., and Coleman, T. P. (2018). Inhome sleep recordings in military veterans with posttraumatic stress disorder reveal less rem and deep sleep $<1 \mathrm{~Hz}$. Front. Hum. Neurosci. 12:196. doi: 10.3389/fnhum.2018.00196

Osuch, E. A., Benson, B. E., Luckenbaugh, D. A., Geraci, M., Post, R. M., and McCann, U. (2009). Repetitive TMS combined with exposure therapy for PTSD: a preliminary study. J. Anxiety Disord. 231, 54-59. doi: 10.1016/j.janxdis.2008.03.015

Ouyang, M., Young, M. B., Lestini, M. M., Schutsky, K., and Thomas, S. A. (2012). Redundant catecholamine signaling consolidates fear memory via phospholipase C. J. Neurosci. 326, 1932-1941. doi: 10.1523/JNEUROSCI.5231-11.2012

Pan, X., Wang, Z., Wu, X., Wen, S. W., and Liu, A. (2018). Salivary cortisol in post-traumatic stress disorder: a systematic review and meta-analysis. BMC Psychiatry 181:324. doi: 10.1186/s12888-018-1910-9

Pezze, M., and Feldon, J. (2004). Mesolimbic dopaminergic pathways in fear conditioning. Prog. Neurobiol. 745, 301-320. doi: 10.1016/j.pneurobio.2004.09.004

Pollard, H. B., Shivakumar, C., Starr, J., Eidelman, O., Jacobowitz, D. M., Dalgard, C. L., et al. (2016). "Soldier's Heart": a genetic basis for elevated cardiovascular disease risk associated with post-traumatic stress disorder. Front. Mol. Neurosci. 9:87. doi: 10.3389/fnmol.2016.00087

Rao, M. L., Strebel, B., Halaris, A., Gross, G., Braunig, P., Huber, G., et al. (1995). Circadian rhythm of vital signs, norepinephrine, epinephrine, thyroid hormones, and cortisol in schizophrenia. Psychiatry Res. 571, 21-39.

Rebecca, C., and Hendrickson, M. A. R. (2016). Noradrenergic dysregulation in the pathophysiologyof PTSD. Exp. Neurol. 284, 181-195. doi: 10.1016/j.expneurol.2016.05.014

Rhind, S., Rakesh, J., Richardson, D., Battista, A. D., and Lanius, R. (2017). Dysregulation of hypothalamic-pituitary-adrenal axis and sympathoadrenergic system is associated with posttraumatic stress disorder in combat veterans. Biol. Psychiatry 8110:S394. doi: 10.1016/j.biopsych.2017.02.700

Schnyder, U., Muller, J., Morina, N., Schick, M., Bryant, R. A., and Nickerson, A. (2015). A. comparison of DSM-5 and DSM-IV diagnostic criteria for posttraumatic stress disorder in traumatized refugees. J. Trauma Stress 284, 267-274. doi: 10.1002/jts.22023
Sher, L., Oquendo, M. A., Li, S., Burke, A. K., Grunebaum, M. F., Zalsman, G., Huang, Y. Y., and Mann, J. J. (2005). Higher cerebrospinal fluid homovanillic acid levels in depressed patients with comorbid posttraumatic stress disorder. Eur. Neuropsychopharmacol. 152, 203-209. doi: 10.1016/j.euroneuro.2004.09.009

Spivak, B., Vered, Y., Graff, E., Blum, I., Mester, R., and Weizman, A. (1999). Low platelet-poor plasma concentrations of serotonin in patients with combat-related posttraumatic stress disorder. Biol. Psychiatry 457, 840-845. doi: 10.1016/S0006-3223(98)00231-5

Strawn, J. R., Pyne-Geithman, G. J., Ekhator, N. N., Horn, P. S., Uhde, T. W., Shutter, L. A., et al. (2010). Low cerebrospinal fluid and plasma orexin-A (hypocretin-1) concentrations in combat-related posttraumatic stress disorder. Psychoneuroendocrino 357, 1001-1007. doi: 10.1016/j.psyneuen.2010.01.001

Thoma, M. V., Kirschbaum, C., Wolf, J. M., and Rohleder, N. (2012). Acute stress responses in salivary alpha-amylase predict increases of plasma norepinephrine. Biol. Psychol. 913, 342-348. doi: 10.1016/j.biopsycho.2012.07.008

Videlock, E. J., Peleg, T., Segman, R., Yehuda, R., Pitman, R. K., and Shalev, A. Y. (2008). Stress hormones and post-traumatic stress disorder in civilian trauma victims: a longitudinal study. Part II: the adrenergic response. Int. J. Neuropsychopharmacol. 113, 373-380. doi: 10.1017/S1461145707008139

Vidović, A., Grubišić-Ilić, M., Kozarić-Kovačić, D., Gotovac, K., Rakoš, I., Markotić, A., Rabatić, S., et al. (2011). Exaggerated platelet reactivity to physiological agonists in war veterans with posttraumatic stress disorder. Psychoneuroendocrinology 362, 161-172. doi: 10.1016/j.psyneuen.2010.08.005

von Kaenel, R., Schmid, J., Abbas, C. C., Gander, M., Saner, H., and Begre, S. (2010). Stress hormones in patients with posttraumatic stress disorder caused by myocardial infarction and role of comorbid depression. J. Affect. Disord. 121, 73-79. doi: 10.1016/j.jad.2009.05.016

Wingenfeid, K., Whooley, M. A., Neylan, T. C., Otte, C., and Cohen, B. E. (2015). Effect of current and lifetime posttraumatic stress disorder on 24-h urinary catecholamines and cortisol: results from the mind your heart study. Psychoneuroendocrinology 52, 83-91. doi: 10.1016/j.psyneuen.2014.10.023

Yahyavi, S. T., Zarghami, M., Naghshvar, F., and Danesh, A. (2015). Relationship of cortisol, norepinephrine, and epinephrine levels with war-induced posttraumatic stress disorder in fathers and their offspring. Rev. Bras. Psiquiatr. 372, 93-98. doi: 10.1590/1516-4446-2014-1414

Yatham, L. N., Sacamano, J., and Kusumakar, V. (1996). Assessment of noradrenergic functioning in patients with non-combat-related posttraumatic stress disorder: a study with desmethylimipramine and orthostatic challenges. Psychiatry Res. 631, 1-6.doi: 10.1016/0165-1781(96)0 2896-X

Yehuda, R., Siever, L. J., Teicher, M. H., Levengood, R. A., Gerber, D. K., Schmeidler, J., et al. (1998). Plasma norepinephrine and 3-methoxy-4hydroxyphenylglycol concentrations and severity of depression in combat posttraumatic stress disorder and major depressive disorder. Biol. Psychiatry 441, 56-63. doi: 10.1016/S0006-3223(98)80007-3

Young, E. A., and Breslau, N. (2004). Cortisol and catecholamines in posttraumatic stress disorder: an epidemiologic community study. Arch. Gen. Psychiatry 614, 394-401. doi: 10.1001/archpsyc.61.4.394

Zenko, M. Y., Baranova, K. A., and Rybnikova, E. A. (2018). Pathogenetic role of the stress-induced release of glucocorticoid hormones in the development of post-traumatic stress disorder: an experimental study. Dokl. Biol. Sci. 4791, 51-53. doi: 10.1134/S0012496618020059

Zhang, G. Q., Yang, J. X., Zhang, Y. Q., Liang, X., Hu, M., and Fan, J. (2014). Altered neurotransmitter levels with post-traumatic stress disorder. Turk. Neurosurg. 246, 844-848. doi: 10.5137/1019-5149.JTN.8723-13.1

Conflict of Interest Statement: The authors declare that the research was conducted in the absence of any commercial or financial relationships that could be construed as a potential conflict of interest.

Copyright (c) 2018 Pan, Kaminga, Wen and Liu. This is an open-access article distributed under the terms of the Creative Commons Attribution License (CC BY). The use, distribution or reproduction in other forums is permitted, provided the original author(s) and the copyright owner(s) are credited and that the original publication in this journal is cited, in accordance with accepted academic practice. No use, distribution or reproduction is permitted which does not comply with these terms. 